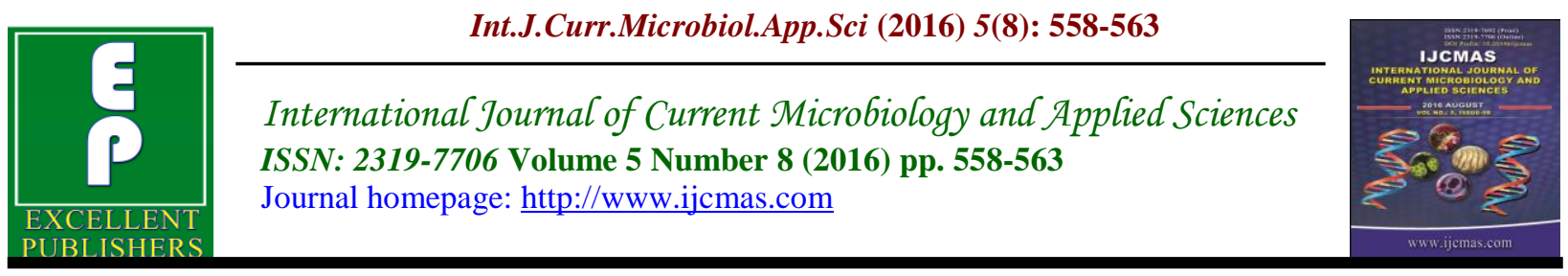

Original Research Article

http://dx.doi.org/10.20546/ijcmas.2016.508.061

\title{
Spectrum of Bacterial Isolates and their Antibiogram Isolated from Pus Sample
}

\author{
Deepali Shivajirao Kamble*, Dnyaneshwari P. Ghadage and Arvind V. Bhore
}

Department of Microbiology, Smt. Kashibai Navale, Medical College and

General Hospital, Narhe, Pune-41, India

*Corresponding author

Keywords

Pus culture,

Sensitivity,

Resistance.

Antibiogram,

Disc diffusion

method.

Article Info

Accepted:

23 July 2016

Available Online:

10 August 2016

\section{A B S T R A C T}

This study was conducted to know the spectrum of bacterial isolates from the pus samples and their sensitivity pattern so that it will help the clinicians to treat patients and help the hospital to have its antibiotic policy. A total 221 pus samples were collected and were processed in the laboratory using standard microbiological procedures. The antibiotic sensitivity testing of all isolates was performed by Kirby Bauer's disc diffusion method and results were interpreted. Out of 221 pus samples $200(90.49 \%)$ samples yielded a positive culture whereas 21(9.50\%) samples yielded no growth. Among 200 samples, 112 (56\%) were male patients and $88(44 \%)$ were female patients. The most predominant Gram positive cocci isolated was Staphylococcus aureus 52(27.65\%) and predominant Gram negative bacteria was Pseudomonas spp $40(21.27 \%)$ apart from other isolates such as Citrobacter spp12 (6.38\%), Escherichia coli 24(12.76\%), Klebsiella spp 28(14.89\%), Proteus spp 12(6.38\%), Methicillin resistant coagulase negative staphylococcus16 (8.51\%) and Acinetobacter spp $16(8.51 \%)$ were also isolated. ESBL was found in $28(21.21 \%)$ and MRSA 15(28.84\%). Gram positive cocci shows $100 \%$ sensitivity to Vancomycin followed by Doxycycline. Whereas Gram negative bacilli were most susceptible to Imipenem followed by Amikacin and Gentamicin.

\section{Introduction}

Infectious diseases remain the most common cause of morbidity and mortality worldwide.

Pyogenic infections are characterized by local and systemic inflammation usually with pus formation. These may be endogenous or exogenous. A break in the skin can provide entry to the surface bacteria which thereby starts multiplying locally. The body's defence mechanism includes bringing immune cells into the area to fight against bacteria. Eventually, accumulation of these cells produces pus which is a thick whitish liquid (Koneman et al., 2005; Chopra et al., 1994). Extensive and sometime, unnecessary use of antimicrobial agents has resulted antibiotic resistance by development of antibiotic resistant genes in many organisms (Sengupta et al., 2001). Emergence of MRSA and ESBL producing 
strains have been observed which confer resistance to commonly used drugs and poses a significant problem in deciding empiric therapy (Shenoy et al., 2010; Palit et al., 2010). Due to these emerging multi drug resistant strains there is need for continuous surveillance of such changing trend of antibiotics and updates knowledge to avoid the unguided empirical treatment. The present study was undertaken to analyze the pattern of pathogens and their antibiotic sensitivity isolated from pus.

\section{Materials and Methods}

The study was conducted from Jan 2015 to June 2015 in tertiary care hospital, Pune. A total 221 pus samples from different departments of tertiary care hospital, Pune were collected using aseptic technique. The specimen were inoculated on Blood agar and Mac-Conkey agar and incubated aerobically at $37^{\circ} \mathrm{C}$ overnight.The isolates were identified by Gram staining, colony morphology and standard biochemical tests:Catalase, Coagulase, Oxidase, Indole production, Methyl red test, VogesProskauer test, Citrate utilization (IMViC tests), $\mathrm{H}_{2} \mathrm{~S}$ production, Urease, Nitrate reduction test and Sugar fermentation tests (Collee et al., 2012).

\section{Antimicrobial susceptibility testing}

Antibiotic susceptibility tests were done on these isolates using Mueller-Hinton agar by standard Disc diffusion method according to CLSI guidelines. The following antibiotics were tested.

Amikacin (30mcg), Ampicillin (30mcg), Cefotaxime (30mcg), Co-trimoxazole (25mcg), Doxycycline (30mcg), Gentamicin (10mcg), Imipenem (10mcg), Piperacillin (100mcg), Ciprofloxacin (5mcg), Vancomycin (10mcg), Penicillin (10units),
Erythromycin (15mcg), Cefoxitin for detection of MRSA and MRCONS (CLSI, 2012).

\section{Detection of ESBL}

This was performed by double disc diffusion method. Test organism were inoculated on Mueller hinton agar. The ceftazidime (30 $\mu \mathrm{g})$ and ceftazidime-clavulanic acid (30 $\mu \mathrm{g} /$ $10 \mu \mathrm{g})$ were placed at a distance of $20 \mathrm{~mm}$ apart on the agar. An increase of $\geq 5 \mathrm{~mm}$ in zone of inhibition of the combination discs in comparison to the ceftazidime disc alone was considered to be ESBL producer (Shiju et al., 2010).

\section{Results and Discussion}

Out of 221 pus samples 200 (90.49 \%) samples yielded a positive culture whereas $21(9.50 \%)$ samples yielded no growth. Among 200 samples, 112 (56\%) were male patients and $88(44 \%)$ were female patients. The most predominant Gram positive cocci isolated was Staphylococcus aureus $52(27.65 \%)$ out of which $15(28.84 \%)$ was MRSA. Most predominant Gram negative bacteria was Pseudomonas spp 40 (21.27\%) apart from other isolates such as Citrobacter spp 12(6.38\%), Escherichia coli 24(12.76\%), Klebsiella spp 28(14.89\%), Proteus spp 12(6.38\%), Methicillin resistant coagulase negative staphylococcus 16 (8.51\%) and Acinetobacter spp 16 (8.51\%) were also isolated.

ESBL was found in 28( 21.21\%). Maximum ESBL producers was observed in E. coli $(37.05 \%)$ followed by Klebsiella spp.(28.57\%), Citrobacter spp and Proteus spp $(16.66 \%)$. While in Acinetobacter spp and Pseudomonas spp $(12.05 \%)$ it was found to be minimum.

The sensitivity of Gram positive cocci shows that Vancomycin $(100 \%)$ was the 
most susceptible drug followed by Doxycycline( $88.23 \%)$.Gram negative bacilli were most susceptible to Imipenem (100\%) followed by Amikacin and Gentamicin (82.60\%). Pseudomonas spp were also susceptible to Imipenem (100\%) and Gentamicin (80\%).

The emergence of resistant strains obtained from pus samples is highly threatening. Organisms associated with pyogenic infection were Staphylococcus aureus, Pseudomonas spp, Escherichia coli, Klebsiella spp. In our study, Staphylococcus aureus was most common Gram positive cocci while in Gram negative bacilli Pseudomonas was most predominant organism which is supported by Duggal et al., Raghav rao et al., and Sowmya et al., $(2015,2014,2014)$ but contrary to the study of Soumya et al., (2014) were Staphylococcus aureus was most common Gram positive cocci and E.coli was most common Gram negative bacilli.

In our study Staphylococcus aureus $(27.65 \%)$ was the most common gram positive cocci as shown in studies of Duggal et al., (2015) and Raghav rao et al., (2014). While MRSA (28.84\%) was shown similar to the study of Soumya et al., (2014) Pseudomonas (29.73\%) was the predominant gram negative bacilli which was similar to the Duggal et al., and Raghav rao et al., studies $(2015,2014)$. Majority of the cases in present study were males $(56 \%)$ which is similar to the study conducted by Duggal et al., were male was $(57.66 \%)$ (2015).

Table.1 ESBL producers among different isolates

\begin{tabular}{|l|l|l|}
\hline Organisms & Total no.of isolates & \% of ESBL producers \\
\hline Pseudomonas $\mathbf{s p p}(\mathbf{n = 4 0})$ & 05 & 12.05 \\
\hline Citrobacter $\mathbf{s p p}(\mathbf{n = 1 2})$ & 02 & 16.66 \\
\hline Esch.coli $(\mathbf{n}=\mathbf{2 4})$ & 09 & 37.05 \\
\hline Klebsiella $\mathbf{s p p}(\mathbf{n = 2 8})$ & 08 & 28.57 \\
\hline Proteus spp $(\mathbf{n = 1 2})$ & 02 & 16.66 \\
\hline Acinetobacter $\mathbf{s p p}(\mathbf{n}=\mathbf{1 6})$ & 02 & 12.05 \\
\hline Total $(\mathbf{n = 1 3 2})$ & $\mathbf{2 8}$ & $\mathbf{2 1 . 2 1}$ \\
\hline
\end{tabular}

The majority of the ESBL producers were E. coli (37.05\%) followed by Klebsiella spp(28.57\%).

Table.2 Antibiotic Susceptibility pattern of Gram positive cocci

\begin{tabular}{|c|c|c|c|c|}
\hline \multirow{2}{*}{ Organism } & \multicolumn{2}{|c|}{ Staphylococcus aureus and Coagulase Negative Staphylococci (n=68) } \\
\cline { 2 - 5 } & \multicolumn{2}{|c|}{ Sensitive } & \multicolumn{2}{c|}{ Resistant } \\
\hline Antibiotics & Number & Percentage & Number & Percentage \\
\hline Co-trimoxazole & 24 & 35.29 & 44 & 64.70 \\
\hline Cefoxitin & 37 & 54.41 & 31 & 45.58 \\
\hline Penicillin & 56 & 82.35 & 12 & 17.64 \\
\hline Doxycycline & 60 & 88.23 & 08 & 11.76 \\
\hline Ciprofloxacin & 39 & 57.35 & 29 & 42.64 \\
\hline Erythromycin & 36 & 52.94 & 32 & 47.05 \\
\hline Vancomycin & 68 & 100 & 00 & 00 \\
\hline
\end{tabular}


Table.3 Antibiotic Susceptibility pattern of Gram Negative bacilli other than Pseudomonas spp.

\begin{tabular}{|c|c|c|c|c|}
\hline \multirow{2}{*}{ Organism } & \multicolumn{3}{|c|}{ Enterobacteriaceae and Acinetobacter spp (n=92) } \\
\cline { 2 - 5 } & \multicolumn{2}{|c|}{ Sensitive } & \multicolumn{2}{c|}{ Resistant } \\
\hline Antibiotics & Number & Percentage & Number & Percentage \\
\hline Amikacin & 76 & 82.60 & 16 & 17.39 \\
\hline Ampicillin & 08 & 08.69 & 84 & 91.30 \\
\hline Cefotaxime & 64 & 69.56 & 28 & 30.43 \\
\hline Co-trimoxazole & 41 & 44.56 & 51 & 55.43 \\
\hline Gentamicin & 76 & 82.60 & 16 & 17.39 \\
\hline Doxycycline & 72 & 78.26 & 20 & 21.73 \\
\hline Ciprofloxacin & 28 & 30.43 & 62 & 07.39 \\
\hline Imipenem & 92 & 100 & 00 & 00 \\
\hline
\end{tabular}

Table.4 Antibiotic Susceptibility pattern of Pseudomonas spp.

\begin{tabular}{|c|c|c|c|c|}
\hline \multirow{2}{*}{ Organism } & \multicolumn{4}{|c|}{ Pseudomonas spp (n=40) } \\
\cline { 2 - 5 } & \multicolumn{2}{|c|}{ Sensitive } & Number & Percentage \\
\hline Antibiotics & Number & Percentage & 12 & 30 \\
\hline Amikacin & 28 & 70 & 08 & 20 \\
\hline Gentamicin & 32 & 80 & 12 & 30 \\
\hline Ciprofloxacin & 28 & 70 & 16 & 40 \\
\hline Piperacillin & 24 & 60 & 20 & 50 \\
\hline Ceftazidime & 20 & 50 & 00 & 00 \\
\hline Imipenem & 40 & 100 & & \\
\hline
\end{tabular}

Graph.1 Sex-wise distribution of positive cultures obtained from pus samples

\section{percentage}

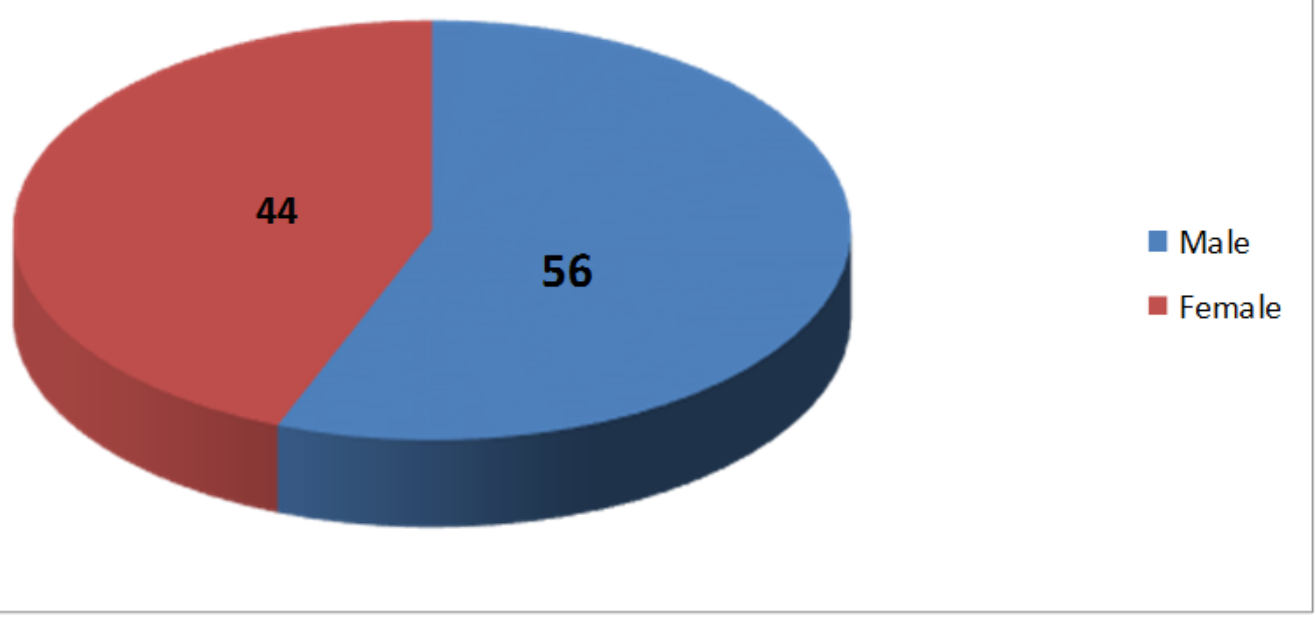


Graph.2 Pie chart showing various bacterial isolates obtained from pus samples

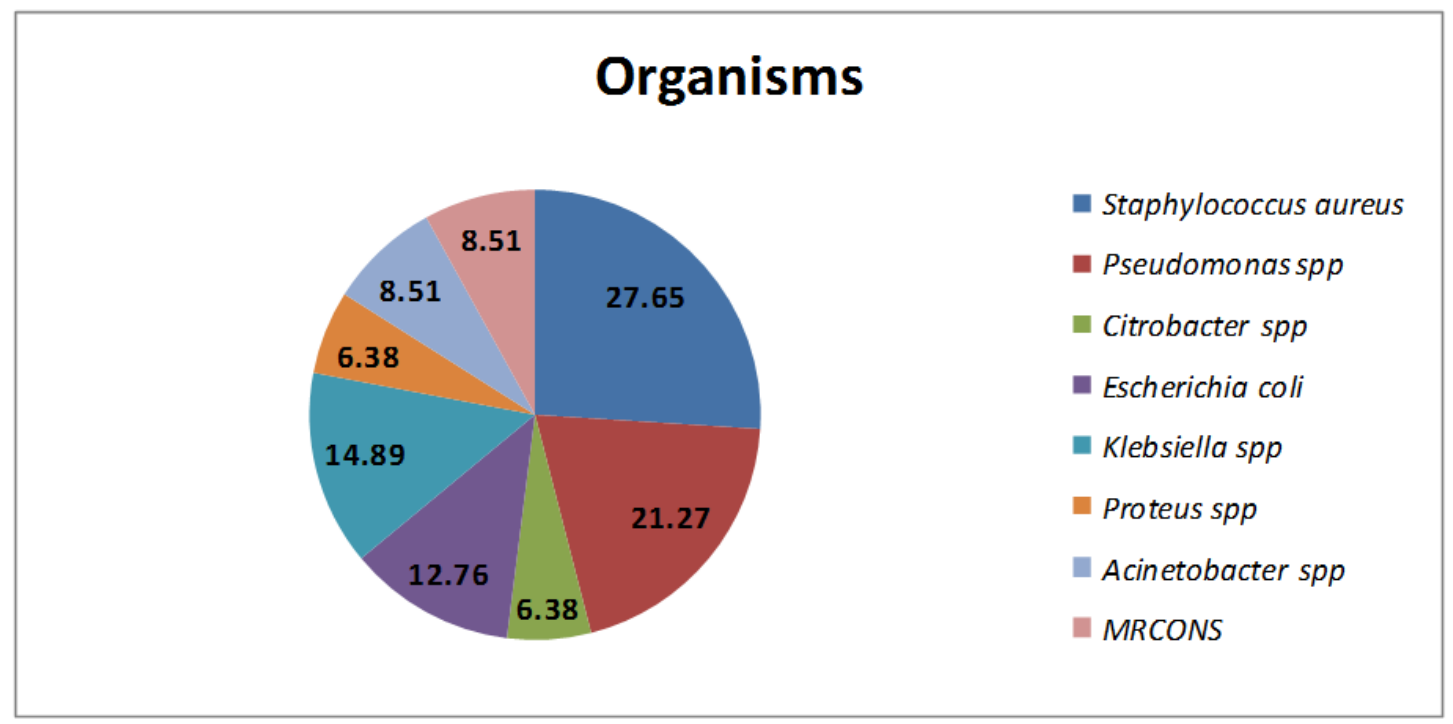

Most predominant Gram positive cocci was Staphylococcus aureus and Gram negative bacilli was Pseudomonas spp.

Staphylococcus aureus was susceptible to Vancomycin (100\%) was similar to Raghav rao et al., (2014) contrary to Duggal et al., study (2015). Antibiotic sensitivity profile of gram negative bacteria showed sensitivity towards imipenem (100\%), and Gentamicin $(48.39 \%)$ as in studies of Raghav rao et al., and Duggal et al., $(2015,2014)$ but different in study conducted by sowmya et al., were gram negative bacteria shows $100 \%$ sensitivity to Imipenem followed by Ciprofloxacin (73\%) (Sowmya et al., 2014). ESBL production was seen in (21.21\%). The ESBL production was found to be E. coli (37.05\%) followed by Klebsiella spp. (28.57\%), Citrobacter spp and Proteus spp $(16.66 \%)$ which was similar to the result obtained Afroz et al., (2014).

In conclusion, pyogenic infection has been major cause of morbidity. The changing trends of antimicrobial susceptibility in bacterial isolates from pus can serve as a useful tool for physicians to start empirical treatment of patients at the earliest according to the geographical areas and emerging multi-resistant bacteria.

\section{References}

Afroz, Z., Metri, B.C., Jyothi, P. 2015. Bacteriological Profile and Antimicrobial Susceptibility Pattern of Skin and Soft Tissue Infections among Gram Negative Bacilli in a Tertiary Care Hospital of South India. $J$. Pharm. Sci. \& Res., Vol. 7(7): 397400.

Chopra, A., Puri, R., Mittal, R., Kanta, S. 1994. A clinical and bacteriological study of pyodermas. Indian $J$. Dermatol. Venereol. Leprol., 60: 2002.

CLSI. 2012. Performance Standards for Antimicrobial Disc Susceptibility Tests;Approved standard 11th edition.CLSI document M02A11.Wayne,PA:Clinical and Laboratory Standards Institute. 
Collee, J.G., Marr, W. 2012. Specimen collection, culture containers \& media. 2012. In : Collee JG, Fraser AG, Marmion BP, Simmons A, editors.Mackie and McCartney's Practical Medical Microbiology. 14 th edition. New Delhi: Elsevier; p 95111.

Duggal, S., Khatri, P.K., Parihar, R.S., Arora, R. 2015. Antibiogram of Various Bacterial Isolates from Pus Samples in a Tertiary Care Centre in Rajasthan. Int. J. Sci. Res., vol4, 5:1580-84.

Koneman, W.K., Allen, S.D., Janda, W.M., Schreckenberger, P.C., Propcop, G.W., Woods, G.L. et al., 2005. Color Atlas and Textbook of Diagnostic Microbiology, $6^{\text {th }}$ ed. LippincottRaven; p624-62.

Palit, A., Inamdar, A.C. 2010. Current concepts in management of bacterial skin infections in children. Indian $J$. Dermatol. Venorol. Leprol., 76: 47688.

Raghav Rao, Basu, R., Biswas, D.R. 2014. Aerobic Bacterial Profile and Antimicrobial Susceptibility Pattern of Pus Isolates in a South Indian Tertiary Care Hospital. J. Dent. Med. Sci., Vol 13,3 : PP 59-62.
Sengupta, S., Human, P., Girag, A.M., Shivananda, P.G. 2001. Acinetobacter: An emergency nosocomial pathogen in the burns unit, Manipal. India Burns, 27: 140-4.

Shenoy, M.S., Bhatt, G.K., Kishore, A., Hassan, M.K. 2010. Significance of MRSA strains in community associated skin and soft tissue infections. Indian J. Med. Microbiol., 28: 152-4.

Shiju, M.P., Yashavanth, R., Narendra, N. 2010. Detection of Extended Spectrum Beta-Lactamase Production and Multidrug Resistance in Clinical Isolates of $E$. coli and $K$. pneumoniae in Mangalore. J. Clin. Diagnos. Res., 4: 2442-2445.

Soumya, K. and Jaya Sankarankutty. 2014. Prevalence and antimicrobial susceptibility patterns of bacteria isolated from skin and wound infections; J. Microbiol. Biotech. Res., 4(2): 39-45.

Sowmya, N., Savitha, S., Mallure, S., Mohanakrishnan, K., Sumathi, G. Arumugam, P. 2014. A two year study of spectrum of bacterial isolates from wound infections by aerobic culture and their antibiotic pattern in a tertiary care center; Int. J. Curr. Microbiol. App. Sci., 3(8): 292-295.

\section{How to cite this article:}

Deepali Shivajirao Kamble, Dnyaneshwari P. Ghadage and Arvind V. Bhore. 2016. Spectrum of Bacterial Isolates and their Antibiogram Isolated from Pus Sample. Int.J.Curr.Microbiol.App.Sci. 5(8): 558-563. doi: http://dx.doi.org/10.20546/ijcmas.2016.508.061 